\title{
PROMOÇÃO CULTURAL \\ E ENSINO: ALGUNS DESAFIOS
}

\section{Os centros de ensino superior poderiam vincular educação e promoção cultural a partir de seus currículos, num esforço de integração dos diversos aspectos da cultura com a prática das salas de aula}

$\mathrm{O}$ que queremos dizer com promoção cultural e ensino? Será que estamos falando em vencer a trama burocrática típica dos centros de ensino e enfrentar a concorrência do mercado, sem dinheiro, e nos dedicar à produção de eventos e à realização concreta de atividades culturais? Estaríamos dispostos e instrumentalizados para produzir eventos e comercializar produtos selecionados?

Poderíamos, talvez, utilizar essa atividade como instrumento de reforço social e legitimação de nós próprios, ou das escolas, prestigiando e divulgando certas idéias e temas de interesse. Escolas e universidades, neste caso, planejariam a oferta de determinados saberes e fazeres organizados, criando oportunidades para a diversificação e ampliação de seu público e de seu espaço de prestígio e atuação.

Porém, o mais desejável seria entender promoção cultural como uma forma de refinamento, de crescimento e de aprofundamento cultural realizado dentro e a partir das questões suscitadas nas escolas.

Se entendêssemos promoção cultural neste sentido, a atividade de ensino estaria entrelaçada com a de promoção cultural e os professores, conscientemente, assumiriam esta responsabilidade. Não estamos diante de possibilidades excludentes ou necessariamente antagônicas em relação aos campos de ação que os centros de ensino podem ocupar. Estamos, entretanto, buscando uma caracterização que justifique e oriente a promoção cultural nos centros de ensino.
Se, por um lado, o desafio da seleção é tão relevante, por outro, temos ignorado a importância disto em relação às próprias instituições de ensino onde trabalhamos. Por exemplo, uma história que pode ser revista e divulgada é justamente a das seleções que ocorreram através dos anos sobre o quê os centros de ensino promovem e como isso vem acontecendo. Tomemos como exemplo a universidade.

Alguém sabe quais os temas, atividades artísticas - da música, artes visuais, literatura ou teatro - e estruturas de organização e debate foram privilegiados por estas instituições? Alguém já analisou a relação entre os tipos de eventos que produzimos e as características do público que participa? Quais interpretações surgiriam se uma análise privilegiasse o estudo das relações entre o que a universidade promove e os currículos e ementas das disciplinas que oferece? Que traços da personalidade cultural de uma determinada escola seriam identificados se investigássemos a história do repertório de promoções selecionadas para oferecer ao público?
A AUTORA
Irene Tourinho
Professora Colaboradora do Departamento de Música da ECA-USP. Doutora em Educação Mu- sical pela Universidade de Wisconsim - Madison, EUA. 


\section{CONSCIÊNCIA CULTURAL}

É inevitável que na definição de currículo e na organização de eventos que possam dialogar com a prática educativa, a seleção - como ela é feita e quem a faz é um dos desafios fundamentais e constantes para a promoção cultural. Enfrentar este desafio traria, como resultado, o desvendamento dos princípios que modelam a atividade coletiva dos centros de ensino. São esses princípios que orientam a formação da consciência cultural que a escola legitima. Refiro-me aqui à consciência não "como um eixo psicológico individual, mas como um eixo sócio-histórico, determinado em sua existência pelos mecanismos objetivos da atividade sócio-produtiva dos indivíduos"l.

Estamos pensando numa vinculação mais explícita entre educação e promoção cultural, criada a partir de e com base nas opções curriculares que fazemos e na importância disso para a formação da consciência cultural dos alunos e professores dos centros de ensino.

Nesse sentido, enfrentaríamos o fato de que as escolas são também espaços-alvo para um tipo de propaganda cultural, para a legitimação de certos produtos e para o fortalecimento de certos parâmetros estéticos.

Como centros de ensino e, portanto, preocupados com a formação da consciência dos indivíduos, estas instituições demonstram, através das seleções que fizeram e fazem, seu nível de comprometimento com aquilo que poderíamos chamar de "justiça cultural". Justiça cultural seria uma dimensão do esforço dedicado a selecionar e integrar tópicos suficientemente diversos da cultura com a prática das salas de aula.
À primeira vista, pensar em centros de ensino como espaço de propaganda cultural pode causar espanto e rejeição. Acontece que as análises sobre o cotidiano das escolas e as opções práticas que têm desenvolvido, vêm demonstrando que, conscientemente ou não, as ações que as escolas desenvolvem reforçam e legitimam determinadas perspectivas de mundo, contribuindo para formar concepções, atitudes e tipos de envolvimento específicos com certos produtos culturais.

As instituições de ensino perderam, em grande escala, seu status de lugar primordial e fonte do conhecimento ou da informação. Não é sem razão que tentamos pensar em novos métodos, novos materiais, novas formas de relacionamento professor/aluno, ou novas disciplinas e formas de fazê-las entrar para as escolas. Fundamentalmente, é a função da escola que está continuamente sendo repensada.

$\mathrm{O}$ acúmulo de informações e a rapidez com que novas informações são produzidas e revisadas interferiu na própria concepção de escola, de ensino, de aprendizagem e de cultura. Paradoxalmente, o nosso tempo de permanência na escola não se alterou. Além disso, sabemos ainda pouco sobre as alterações da capacidade humana de absorção e compreensão de conhecimentos. Para apreender e refletir sobre um número imensamente maior de novas informações e formas de produzi-las, continuamos passando na escola o mesmo tempo que passávamos dezenas de anos atrás. Aliás, como a relação mestre/aprendiz, antes, era marcada pela convivência diária, contínua e prolongada, poderíamos dizer que o tempo dedicado à escolarização até diminuiu.

Além do desafio da seleção, amparado por uma visão crítico-histórica e pela

1. TOLSTYJ, V.I. La producción espiritual. La Habana: Editorial de Ciencias Sociales, 1989, p.120. 
"justiça cultural" como princípio ativo do planejamento e organização das atividades, citaríamos um outro desafio que é o da continuidade. A falta de continuidade de ações e projetos que impera nesse país não se limita à área da cultura. Estamos tão acostumados com novos nomes em novos cargos que, se qualquer iniciativa consegue chegar mesmo a uma segunda versão, já merece aplausos. Dar continuidade ao trabalho de promoção cultural, vendo isso a partir do papel dos professores de arte e artistas profissionais típicos dos centros de ensino preocupados com a promoção cultural significa criar, no dia-a-dia, oportunidades de investigação e crítica tanto do que se promove dentro quanto fora desses centros.

Não significa apenas promover a discussão e o debate com convidados. Promover o debate aberto e público entre alunos, com assistência e crítica de colegas e professores é uma forma de incentivar a produção de idéias e a consciência das necessidades de reflexão de cada escola. A continuidade acontece, primordialmente, através dessa prática e do questionamento entre alunos e professores.

\section{OMISSÃO E FALTA DE DEBATE}

A promoção cultural como complemento e parte da educação significa promover espetáculos, debates ou exposições, com responsabilidade e autonomia para banalizar, reforçar ou repensar o que é promovido dentro e fora dos centros de ensino.

É a convivência intelectual, publicamente expressa entre professores e alunos, que poderá assegurar o surgimento de uma demanda por qualidade e continuidade das atividades culturais que as escolas e outros centros possam promover.

Vencendo a tentação de reduzir a falta de continuidade apenas à falta de dinheiro, outros fatores poderiam ser apontados co- mo interferindo nesses processos. Por exemplo, a perspectiva viciada dos centros de ensino em relação a quem pode participar e contribuir no planejamento dos eventos, a tendência a querer fazer atividades grandiosas, a falta de divulgação e a falta de comprometimento de muitos dos profissionais envolvidos. Temos que admitir que, internamente, vivemos um tipo de cultura nos centros de ensino que é, muitas vezes, adversa à formação da consciência e da promoção cultural que poderíamos incentivar. Já que o nosso tema é promoção cultural, vale a pena refletir um pouco sobre alguns elementos do que se poderia chamar como "cultura dos centros de ensino" para ver em que condições podem nascer e se desenvolver os projetos de formação e promoção cultural.

Um primeiro dado conhecido da nossa cultura, principalmente universitária, é nossa capacidade para criar clubinhos fechados - igrejinhas, já disseram - nos quais alguns são preferidos e outros excluídos. Muitas vezes, preferências e exclusões não decorrem, como já sabemos, do mérito - mas sim, de oportunidades.

As bases dessas clausuras acadêmicas são, em inúmeras situações, paradigmas enrijecidos ou, pelo menos, tratados como tal. Assim, se um defende, por exemplo, a interdisciplinaridade nos estudos, o outro jamais abandonará seu modelo de especialização, nem para uma simples visita intelectual que, em hipótese, talvez apenas reforçasse seus próprios modelos.

Os excluídos de um determinado círculo intelectual não só deixarão de ter apoio como serão alvo de desejos ocultos de que fracassem naquilo que pretendam promover. Parece absurdo, até ridículo, mas existe um tipo de competição surda, e muda, que só pode nascer de lapsos de nossa percepção sobre o incontável e o inconcebível - em sua totalidade - mundo do pensamento, da 
ação e da sensação. Sem querer psicologizar demais a questão, que medo é esse que nos leva a pensar que o espaço produtivo intelectual é pequeno para que nele caibamos todos nós?

Além da competição e do enrijecimento de certos paradigmas que nos fecham em torno de nós mesmos, uma segunda característica da cultura dos centros de ensino é que temos boa vontade e disposição abundante para criticar - no sentido negativo do termo - , mas nos custa muito contribuir e pensar com os outros e para eles. Pena é que a disposição para tal tipo de crítica geralmente não parte de motivações declaradas.

Falamos muito sobre atividade crítica, necessidade da crítica, ensino crítico, mas a nossa atuação crítica é pouco trabalhada. Optamos pela omissão ou pelo ataque, nem sempre frontal. A omissão tem nos permitido permanecer onde estamos evitando a possibilidade de viver expressamente os conflitos, como se os conflitos fossem desaparecer pelo simples fato de nos recusarmos a enfrentá-los. Se a omissão tem criado barreiras para o debate, o ataque radicaliza nossas atitudes e vem sempre acompanhado da certeza de projetos abortados e relacionamentos desfeitos.

Enclausuramento intelectual, competição sem debate e sem enfrentamento são parte de situações que, sem receio de exagerar, cada um de nós já experimentou. Muitos já foram protagonistas. Ao lado disso, e colaborando para sustentar essas condições, temos mantido ao mínimo nossos esforços para trabalhar coletivamente. Assim é que nosso tempo para o trabalho individual é sagrado; para o coletivo, é a sobra. Raramente dedicamos nosso tempo para discutir as questões mais prementes e relevantes da nossa profissão e freqüentemente nos reunimos, com a demora e o imobilismo que todos repudiamos, para tratar de assuntos redundantes, pequenos e, às vezes, fúteis.
O que parece temperar essa mistura de fatores que compõem a cultura dos centros de ensino é um personalismo exacerbado coisa que Mário de Andrade, Fernando de Azevedo, Alfredo Bosi e outros intelectuais por quem nossa cultura deve maior apreço, já apontaram.

Esse personalismo impede movimentos de resistência e de mudança e nos abate. Passamos a viver "infelizmente satisfeitos", ou "satisfatoriamente infelizes", uma contradição que aponto para indicar a existência de uma luta interna entre querer mudar e permanecer vivendo dos "méritos" que a vida intelectual institucionalizada oferece.

\section{PRODUÇÃO E PARTICIPAÇÃO}

É certo que a cultura dos centros de ensino não é formada apenas das oscilações entre conformismo, individualismo, omissão e descompromisso. Tem um lado de energia e vitalidade produtiva que alimenta nossas satisfações e vontade de trabalhar. Tem ainda um lado próprio da cultura dos alunos, muitas vezes dependentes e passivos em relação às formas de ensino e aprendizagem que recebem e promovem; outras vezes responsavelmente irreverentes e ousados para influenciar e transformar o curso de determinados processos.

Configurando a cultura da escola, temos ainda as características que compõem o relacionamento professor/aluno, o cotidiano vivido nas salas de aulas e nos corredores: as avaliações de uns sobre outros, formadas e às vezes refeitas ao longo da convivência escolar. $\mathrm{O}$ que tudo isso tem a ver com os desafios para a promoção cultural nos nossos ambientes de trabalho é que desconhecemos, damos pouca importância, ou camuflamos a nossa própria cultura. Não sou da opinião de que, para promover, precisaríamos primeiro nos conhecer. Penso, entretan- 
to, que um processo de desvendamento de uma cultura e sua discussão, mantida com uma visão dialógica entre a cultura que se analisa e as culturas circundantes, é parte daquilo que entendo por promoção cuitural em centros de ensino.

É, também, um caminho para a necessária institucionalização das atividades culturais que queremos promover. Isso porque é o fruto da interferência dos "piores" fatores que constituem a nossa cultura escolar que resulta, muitas vezes, numa produção desalinhada, sem vinculações claras com o nosso trabalho diário de educação. Contribuímos para uma quase (des)institucionalização do trabalho cultural, matando muitas iniciativas que poderiam servir de questionamento ou transformar nossa prática pedagógica.

Poderíamos seguir ou deixar que o leitor divagasse nesse universo cultural que é a vida interna dos centros de ensino e as implicações que têm para o trabalho de promoção cultural. De toda maneira, sugerimos que como promoção cultural levemos em conta esse estudo das nossas formas de convivência - ou não convivência - o diálogo escrito sobre as produções dos nossos colegas e a participação ativa nos eventos que nossos colegas e alunos se esforçam por produzir.

Entendendo a promoção cultural não como um fim mas como um produto da ocupação de professores e alunos com a própria cultura - inclusive aquela que internamente criam - que penso deva residir a ação dos centros de ensino.

Mas há um outro desafio, o último, que vale mencionar: refiro-me ao desafio da memória. Esse desafio significa mais do que o trabalho crítico sobre a história das produções e o estudo sobre a cultura interna e externa nos centros de ensino.

Pensamos o desafio da memória através de pelo menos dois ângulos. $\mathrm{O}$ primeiro se traduz numa resistência à nossa tendência de sempre querer promover o - presumidamente - novo. E como se a pretensão ao originalismo ou vanguardismo nos perseguisse tanto que nos fizesse esquecer o prazer que representa rever ou reconhecer um antigo conhecido. Esquecemos também que são muitos os olhos com os quais podemos olhar um fenômeno vivido. $\mathrm{O}$ desafio da memória, nesse sentido, seria aquele impulso para ousar revisar interpretações de velhos fatos, propor releituras de antigas celebrações e conceber reapresentações de formas já conhecidas de expressão. Seria resistir aos preconceitos com o passado porque, para a memória, o passado representa possibilidades de um presente que se mantém sempre infindo. Representa um olhar versátil que descobre outros enquanto viaja no tempo.

Finalmente, pensamos o desafio da memória num sentido que seria justamente a produção da memória dos eventos que os promovem. Isso significa pensar o evento além do seu tempo de público, até seu registro e documentação possível de circulação entre outros públicos. É através da produção material da memória dos eventos que criamos a possibilidade de retomá-los para fazer deles uma parte do cotidiano da escola. Nesse sentido, a promoção cultural como formação da consciência deve garantir que um número maior de pessoas possa, independentemente da presença física, beneficiar-se do esforço conjunto de apreciar e pensar a cultura. Essa garantia depende, obviamente, do registro e da distribuição da memória desses eventos.

A intenção de promover cultura dentro dos centros de ensino deve mexer com as formas de vida do próprio centro e do ensino que acontece ali. Não há regras fixas para esta ou para outra atividade humana. Os desafios que tratamos serão, provavelmente, desafios que sempre existirão e serão enfrentados de maneiras diversas em cada escola. 
A seleção, a continuidade, a capacidade de lidar com outras épocas e povos e a responsabilidade de organizar a memória do que fazemos não são trabalhos de um pequeno grupo de profissionais. São os centros que se transformam em escolas, laboratórios, salas de estudo e convivência, privilegiando a observação, experimentação e formas de documentação sobre as e a partir das atividades culturais.

Para enfrentarmos esses e outros desafios, temos uma enorme vantagem. O fato de sermos das áreas artísticas e da educação coloca-nos numa posição das mais efetivas para realizar a promoção cultural.
Primeiro porque representamos a ligação mais direta e forte da crença no envolvimento dos indivíduos com seus símbolos, linguagens e produtos estéticos. Depois porque as caras que os centros de ensino mostram, têm sempre na arte, ou na educação, sua forma de apelo mais eficaz. E por último, porque nossas maneiras de contagiar um povo são tão diversas quanto ele próprio o é. Talvez aqui resida o maior prazer de todos os nossos desafios: como seres culturais, somos feitos da nossa coletividade e vivemos dela e para ela. Este prazer vence e se sobrepõe aos erros que cometemos. Como este prazer não parece ter fim, nossa vontade de promover a cultura seguirá nos acompanhando. 